\title{
In vitro and in vivo bactericidal activity of ceftazidime-avibactam against Carbapenemase-producing Klebsiella pneumoniae
}

Wenxia Zhang ${ }^{1,2+}$, Yan Guo ${ }^{1,4 \dagger}$, Jiayin $\mathrm{Li}^{3 \dagger}$, Yiyuan Zhang ${ }^{3}$, Yang Yang ${ }^{1,4}$, Dong Dong ${ }^{1,4}$, Demei Zhu ${ }^{1,4}$, Ping $\mathrm{He}^{3^{*}}$ and Fupin $\mathrm{Hu}^{1,4^{*}}$

\begin{abstract}
Background: In recent years, the incidence of carbapenem-resistant Enterobacteriaceae (CRE) infections has increased rapidly. Since the CRE strain is usually resistant to most of antimicrobial agents, patients with this infection are often accompanied by a high mortality. Therefore, it instigates a severe challenge the clinical management of infection. In this study, we study the in vitro and in vivo bactericidal activity of ceftazidime-avibactam administrated either alone or in combination with aztreonam against KPC or NDM carbapenemase-producing Klebsiella pneumoniae, and explore a new clinical therapeutic regimen for infections induced by their resistant strains.

Methods: The microdilution broth method was performed to analyze the minimal inhibitory concentration (MIC). The time-kill curve assay of ceftazidime-avibactam at various concentrations was conducted in 16 strains of KPC-2 and 1 strain of OXA-232 carbapenemase-producing Klebsiella pneumoniae. The in vitro synergistic bactericidal effect of ceftazidime-avibactam combined with aztreonam was determined by checkerboard assay on 28 strains of NDM and 2 strains of NDM coupled with KPC carbapenemase-producing Klebsiella pneumoniae. According to calculating grade, the drugs with synergistic bactericidal effect were selected as an inhibitory concentration index. The in vitro bactericidal tests of ceftazidime-avibactam combined with aztreonam were implemented on 12 strains among them. Effect of ceftazidime-avibactam antibiotic against KPC carbapenemase-producing K. pneumoniae strain Y8 Infection was performed in the mouse model.
\end{abstract}

(Continued on next page)

\footnotetext{
* Correspondence: hpatsh@sjtu.edu.cn; hufupin@fudan.edu.cn

tWenxia Zhang, Yan Guo and Jiayin Li contributed equally to this work.

${ }^{3}$ Department of Medical Microbiology and Immunology, Shanghai Jiao Tong University School of Medicine, Shanghai 200025, China

'Institute of Antibiotics, Huashan Hospital, Fudan University, 12 M. Wulumuqi Rd, Shanghai 200040, China

Full list of author information is available at the end of the article
}

(c) The Author(s). 2018 Open Access This article is distributed under the terms of the Creative Commons Attribution 4.0 International License (http://creativecommons.org/licenses/by/4.0/), which permits unrestricted use, distribution, and reproduction in any medium, provided you give appropriate credit to the original author(s) and the source, provide a link to the Creative Commons license, and indicate if changes were made. The Creative Commons Public Domain Dedication waiver (http://creativecommons.org/publicdomain/zero/1.0/) applies to the data made available in this article, unless otherwise stated. 


\begin{abstract}
(Continued from previous page)
Results: The time-kill assays revealed that ceftazidime-avibactam at various concentrations of 2MIC, 4MIC and 8MIC showed significant bactericidal efficiency to the resistant bacteria strains. However, in 28 strains of NDM and 2 strains of NDM coupled with KPC carbapenemase- producing Klebsiella pneumoniae, only 7 strains appeared the susceptibility to ceftazidime-avibactam treatment, $\mathrm{MIC}_{50}$ and $\mathrm{MIC}_{90}$ were $64 \mathrm{mg} / \mathrm{L}$ and $256 \mathrm{mg} / \mathrm{L}$, respectively. Antimicrobial susceptibility testing of ceftazidime-avibactam combined with aztreonam disclosed the synergism of two drugs in $90 \%$ (27/30) strains, an additive efficiency in 3.3\% (1/30) strains, and irrelevant effects in 6.6\% (2/30) strains. No antagonism was found. The subsequent bactericidal tests also confirmed the results mentioned above. Therapeutic efficacy of Ceftazidime-Avibactam against $K$. pneumoniae strain Y8 infection in mouse indicated $70 \%$ of infection group mice died within 4 days, and all mice in this group died within 13 days. Bacterial load testing results showed that there was no significant difference in the amount of bacteria in the blood between the infected group and the treatment group. However, the spleen and liver of treatment group mice showed lower CFU counts, as compare with infected group, indicating that ceftazidime-avibactam has a significant effect on the bacteria and led to a certain therapeutic efficacy.

Conclusion: This study indicated ceftazidime-avibactam therapy occupied significant bactericidal effects against KPC-2 and OXA-232 carbapenemase-producing Klebsiella pneumoniae. While combined with aztreonam, the stronger synergistic bactericidal effects against NDM carbapenemase-producing Klebsiella pneumoniae were achieved.
\end{abstract}

Keywords: Klebsiella pneumoniae, Carbapenemase, Ceftazidime-avibactam, Aztreonam, Time-kill curve assay

\section{Background}

Carbapenems are considered the most effective antibacterial agents against infections caused by multi-drug resistant gram-negative bacillus in clinical practice. However, with the broad use of carbapenems, and the emergence and widespread of carbapenem-resistant Enterobacteriaceae (CRE), in particular carbapenem-resistant Klebsiella pneumoniae (CR-KP), the clinical anti-infection treatment faces a drugfree dilemma [1-4]. Previous studies have shown that the most important resistant mechanism of CR-KP to carbapenems is production of carbapenemases including class A KPC carbapenemases, class B metallo- $\beta$-lactamases and class D OXA-48 family carbapenemases. Avibactam is a newly developed novel $\beta$-lactamase inhibitor in recent years and can efficiently inhibit class A and class D carbapenemases. As an inhibitor, avibactam can restore the antibacterial activity of ceftazidime to CR-KP. Nevertheless, it has less antibacterial efficiency against CR-KP with metallo- $\beta$-lactamase [5-7]. Knowing that aztreonam is stable against hydrolysis by class B metallo- $\beta$-lactamases, we hypothesized that supplement of aztreonam to the ceftazidime-avibactam would enhance the activity by "protecting" aztreonam from the "attack" of KPC type carbapenemase. This study aims to explore a new therapeutic regimen by administration of ceftazidimeavibactam alone or combined with aztreonam against carbapenemase-producing Klebsiella pneumoniae.

\section{Materials and methods}

\section{Strains}

A total of 47 non-repeated clinical strains of carbapenemase-producing Klebsiella pneumoniae were collected from 9 hospitals in 9 cities in China. Of these, 16 strains were $b l a_{\mathrm{KPC}-2}$ positive, 1 was $b l a_{\mathrm{OXA}-232}$ positive, 28 were $b l a_{\mathrm{NDM}}$ positive, and 2 were $b l a_{\mathrm{KPC} 2}$ coupled with bla NDM positive Klebsiella pneumoniae. All strains were identified by mass spectrometry and the gene type of carbapenemases was analyzed by PCR amplification using primers previously described and DNA sequencing [8-10]. E. coli ATCC 25922 were used as quality control strain for antimicrobial susceptibility testing. One $K$. pneumoniae clinical strain $\mathrm{Y} 8$ was used for the Infection in the mouse model.

\section{Antimicrobial susceptibility testing}

The minimal inhibitory concentrations were determined by microbroth dilution according to Clinical and Laboratory Standards Institute (CLSI) guidelines [11]. The in vitro synergistic bactericidal effects of ceftazidimeavibactam combined with aztreonam against $b l a_{\mathrm{NDM}}$-positive strains were determined by checkerboard assay referred to the published reports $[12,13]$. The calculation and interpretation of fractional inhibitory concentration (FIC) was referred to the document standards [14]. FIC $=\mathrm{MIC}_{\text {drug A }} /$ $\mathrm{MIC}$ drug A plus drug B $+\mathrm{MIC}_{\text {drug } \mathrm{B}} / \mathrm{MIC}$ drug A plus drug $\mathrm{B}$. FIC $\leq 0.5$ was considered as a synergistic effect, $0.5<$ FIC $\leq$ 1 was considered as an additive effect, $1<$ FIC $\leq 2$ was considered as an irrelevant effect, and $>2$ was considered as an antagonism.

\section{Time-kill assay}

According to the minimal inhibitory concentration (MIC) of ceftazidime-avibactam to $b l a_{\mathrm{KPC}-2}$ or $b l a_{\mathrm{OXA}-232}$ producers, the bactericidal effects of ceftazidime-avibactam at various concentrations of $0.5 \mathrm{MIC}, 1 \mathrm{MIC}, 2 \mathrm{MIC}, 4 \mathrm{MIC}$ and $8 \mathrm{MIC}$ were studied by time-kill assay. In line with the results of antimicrobial susceptibility testing of ceftazidimeavibactam combined with aztreonam, and following the 
methods recommended in literatures [15, 16], 10 Klebsiella pneumoniae strains with bla $a_{\mathrm{NDM}}$ and 2 Klebsiella pneumoniae strains with $b l a_{\mathrm{NDM}}$ coupled with $b l a_{\mathrm{KPC}-2}$ were randomly selected for synergistic bactericidal effects. The operation procedure is briefly described as follows: Mueller-hinton broth containing $1 \times 10^{5} \mathrm{CFU} / \mathrm{mL}$ bacteria is mixed with single or combined antimicrobial agents incubated overnight with consecutive shacking at $35^{\circ} \mathrm{C}$ in an atmospheric environment. Meanwhile, the same broth without antibiotics was served as a growth control. Broth samples were serially diluted at times of $0,2,4,6,8$ and $10 \mathrm{~h}$ and smeared on a mueller-Hinton plate respectively. After overnight incubation at $35^{\circ} \mathrm{C}$, the colonies were counted. If the reduction of bacterial survival amount in sample treated with combined antibiotics was $\geq 2 \log 10$ $\mathrm{CFU} / \mathrm{mL}$ than those in the sample treated by single drug, it was considered to have a synergistic bactericidal effect.

\section{Effect of ceftazidime-avibactam against $K$. pneumoniae strain $\mathrm{Y} 8$ infection in the mouse model}

Six-week-old BALB/c mice (female) were bought from Shanghai Laboratory Animal Company (SLAC), China. Animal experiments were performed in accordance with the Animal Ethics Committee of Shanghai Jiao Tong University. Groups of 10 mice were infected with $2.5 \times$ $10^{6} \mathrm{CFU}$ of strain Y8 via the intraperitoneal (ip) route. Then mice were treated with PBS (infection group) or ceftazidime-avibactam (treatment group) $(0.375 \mathrm{mg} / \mathrm{g}$ of body weight in $0.1 \mathrm{ml}$ PBS) by subcutaneous injection $4 \mathrm{~h}$ post infection and given every $8 \mathrm{~h}$ for 10 days. The survival rates of mice were measured at desired time point to assess the therapeutic efficacy of ceftazidime-avibactam. Survival curves were monitored for 15 days.

\section{Bacterial load in the blood and tissues of mice}

To measure the efficacy of this drug, the bacterial load was measured in the blood and tissues of mice. Groups of 8 mice were infected with $2.5 \times 10^{6} \mathrm{CFU}$ of strain $\mathrm{Y} 8$ via the ip and then treated with PBS or ceftazidime-avibactam by subcutaneous injection. The antibiotic dosage and administration were same as the survival experiment mentioned above. At 3 days post infection (dpi), mice in treatment and infected group were euthanized, and the blood and tissues of mice were removed to determine the bacterial burden through bacterial dilution-plate method.

\section{Results}

Antimicrobial susceptibility testing

All 16 Klebsiella pneumoniae strains with $b l a_{\mathrm{KPC}-2}$ were susceptible to ceftazidime-avibactam with MIC range for 4-8 $\mathrm{mg} / \mathrm{L}$. However, all of strains were resistant to ceftazidime with $\mathrm{MIC}_{50}$ of $32 \mathrm{mg} / \mathrm{L}$ and $\mathrm{MIC}_{90}$ of $>256 \mathrm{mg} / \mathrm{L}$. The resistance rate of imipenem was $93.8 \%$ with $\mathrm{MIC}_{50}$ and $\mathrm{MIC}_{90}$ for $64 \mathrm{mg} / \mathrm{L}$ and $128 \mathrm{mg} / \mathrm{L}$, respectively. The resistance rate of meropenem was $93.8 \%$ with $\mathrm{MIC}_{50}$ and $\mathrm{MIC}_{90}$ for $64 \mathrm{mg} / \mathrm{L}$ and $256 \mathrm{mg} / \mathrm{L}$, respectively (Table 1 ).

Table 1 Minimal inhibitory concentration (MIC) of ceftazidime-avibactam against KPC-2 or OXA-232 carbapenemase-producing Klebsiella pneumoniae

\begin{tabular}{|c|c|c|c|c|c|c|c|}
\hline \multirow[t]{2}{*}{ Strain no. } & \multirow[t]{2}{*}{ Bacteria } & \multirow{2}{*}{$\begin{array}{l}\beta- \\
\text { lactamase }\end{array}$} & \multicolumn{4}{|c|}{$\mathrm{MIC}(\mathrm{mg} / \mathrm{L})$} & \multirow[t]{2}{*}{ Associated $\beta$-lactamase } \\
\hline & & & CAZ-AVI & CAZ & IPM & MEM & \\
\hline R16- Hefei & K. pneumoniae & KPC-2 & 8 & 128 & 64 & 64 & CTX-M-14, SHV-11, DHA-1 \\
\hline R18- Hefei & K. pneumoniae & KPC-2 & 4 & 128 & 8 & 16 & SHV-28, DHA-1 \\
\hline R19- Hefei & K. pneumoniae & KPC-2 & 4 & 128 & 16 & 16 & SHV-12, DHA-1 \\
\hline R31- Beijing & K. pneumoniae & $\mathrm{KPC}-2$ & 8 & 128 & 64 & 256 & SHV-11, DHA-1 \\
\hline R35- Beijing & K. pneumoniae & KPC-2 & 8 & 128 & 128 & 256 & SHV-11, DHA-1 \\
\hline R39-Fuzhou & K. pneumoniae & KPC-2 & 8 & $>256$ & 32 & 64 & CTX-M-14, SHV-12, DHA-1 \\
\hline R42- Fuzhou & K. pneumoniae & $\mathrm{KPC}-2$ & 8 & $>256$ & 32 & 64 & CTX-M-14, SHV-12, DHA-1 \\
\hline R44- Fuzhou & K. pneumoniae & KPC-2 & 8 & $>256$ & 64 & 128 & CTX-M-14, SHV-12, DHA-1 \\
\hline R46- Fuzhou & K. pneumoniae & KPC-2 & 8 & $>256$ & 64 & 64 & SHV-12, DHA-1 \\
\hline R52- Fuzhou & K. pneumoniae & $\mathrm{KPC}-2$ & 8 & $>256$ & 64 & 128 & CTX-M-14, SHV-12, DHA-1 \\
\hline R53- Fuzhou & K. pneumoniae & KPC-2 & 8 & $>256$ & 64 & 128 & CTX-M-14, SHV-12, DHA-1 \\
\hline R59- Hangzhou & K. pneumoniae & KPC-2 & 8 & 32 & 8 & 16 & CTX-M-14, SHV-11, DHA-1 \\
\hline R60- Hangzhou & K. pneumoniae & KPC-2 & 4 & 32 & 4 & 4 & CTX-M-14, SHV-11, DHA-1 \\
\hline JSD-Shanghai & K. pneumoniae & KPC-2 & 8 & 128 & 128 & 512 & CTX-M-14, SHV-11, DHA-1 \\
\hline WJQ-Shanghai & K. pneumoniae & $\mathrm{KPC}-2$ & 8 & $>256$ & 128 & 256 & CTX-M-14, SHV-11, DHA-1 \\
\hline LDX-Shanghai & K. pneumoniae & $\mathrm{KPC}-2$ & 8 & $>256$ & 32 & 64 & CTX-M-55, SHV-31, DHA-1 \\
\hline PED-Shanghai & K. pneumoniae & OXA-232 & 2 & $>32$ & 1 & 4 & CTX-M-15, SHV-1 \\
\hline
\end{tabular}


The MIC of ceftazidime-avibactam to one OXA-232 carbapenemase-producing Klebsiella pneumoniae was $2 \mathrm{mg} / \mathrm{L}$. The resistance rate of ceftazidime-avibactam to 30 bla $_{\mathrm{NDM}}$ (including NDM plus KPC-2) positive Klebsiella pneumoniae strains was $76.7 \%$ with MIC range for 0.5 $256 \mathrm{mg} / \mathrm{L}, \mathrm{MIC}_{50}$ and $\mathrm{MIC}_{90}$ for $64 \mathrm{mg} / \mathrm{L}$ and $256 \mathrm{mg} / \mathrm{L}$, respectively. The MIC range of aztreonam was $8 \sim>$ $256 \mathrm{mg} / \mathrm{L}$ with $\mathrm{MIC}_{50}$ and $\mathrm{MIC}_{90}$ were $128 \mathrm{mg} / \mathrm{L}$ and > $256 \mathrm{mg} / \mathrm{L}$, respectively. Ceftazidime-avibactam combined with aztreonam showed synergistic effects to $90 \%(27 / 30)$ of strains with $b l a_{\mathrm{NDM}}, 3.3 \%(1 / 30)$ showed additive effects and $6.6 \%(2 / 30)$ showed unrelated effects. No antagonism was found for ceftazidime-avibactam combined with aztreonam (Table 2).

\section{Time-kill assay}

The results of time-kill assays showed that all $b l a_{\mathrm{KPC}-2}$ or bla $a_{\text {OXA-232 }}$ positive $K$. pneumoniae strains rebounded to grow 4 to $6 \mathrm{~h}$ at $0.5 \mathrm{MIC}$ of ceftazidime-avibactam. At the concentration of $1 \mathrm{MIC}$ ceftazidime-avibactam, 23.5\% $(4 / 17)$ of strains declined stably $2 \mathrm{~h}$ after dosing and no colonies were detected at $24 \mathrm{~h}$, however, $76.5 \%(13 / 17)$ of strains rebounded to grow in 4-6h. At the concentrations of $2 \mathrm{MIC}$, $4 \mathrm{MIC}$ or $8 \mathrm{MIC}$ of ceftazidime-avibactam, it

Table 2 Results of MIC and antimicrobial susceptibility testing of ceftazidime-avibactam single dosing and combined with aztreonam against NDM + KPC-2 carbapenemase-producing Klebsiella pneumoniae in 30 strains

\begin{tabular}{|c|c|c|c|c|c|c|c|c|}
\hline \multirow[t]{2}{*}{ Strain no. } & \multirow[t]{2}{*}{ Bacteria } & \multirow[t]{2}{*}{$\beta$-lactamase } & \multicolumn{2}{|c|}{$\begin{array}{l}\text { MIC }(m g / L) \text { single } \\
\text { dosing }\end{array}$} & \multicolumn{2}{|c|}{$\begin{array}{l}\text { MIC (mg/L) Combined } \\
\text { dosing }\end{array}$} & \multirow{2}{*}{$\begin{array}{l}\text { FIC value } \\
\text { ATM + CAZ-AVI }\end{array}$} & \multirow[t]{2}{*}{ Associated $\beta$-lactamase } \\
\hline & & & ATM & CAZ-AVI & ATM & CAZ-AVI & & \\
\hline R078 Anhui & K. pneumoniae & NDM & 256 & 32 & 8 & 1 & 0.06 & SHV-28, DHA-1, CTX-M-15 \\
\hline R080 Hainan & K. pneumoniae & NDM & 128 & 4 & 32 & 0.25 & 0.31 & SHV-11, DHA-1, CTX-M-14 \\
\hline R081 Hainan & K. pneumoniae & NDM & 1024 & 8 & 64 & 2 & 0.31 & SHV-11, DHA-1, CTX-M-14 \\
\hline R082 Hainan & K. pneumoniae & NDM & 256 & 64 & 16 & 1 & 0.08 & $\begin{array}{l}\text { SHV-11, DHA-1, CTX-M-15, } \\
\text { CTX-M-14 }\end{array}$ \\
\hline R083 Hainan & K. pneumoniae & NDM & 128 & 64 & 32 & 0.5 & 0.26 & SHV-12, DHA-1, CTX-M-15 \\
\hline R084 Hainan & K. pneumoniae & NDM & 512 & 64 & 16 & 1 & 0.05 & SHV-12, DHA-1 \\
\hline R085 Hainan & K. pneumoniae & NDM & 1024 & 128 & 32 & 2 & 0.05 & SHV-12, DHA-1, CTX-M-15 \\
\hline R086 Hainan & K. pneumoniae & NDM & 128 & 64 & 16 & 0.5 & 0.13 & SHV-12, DHA-1, CTX-M-15 \\
\hline R088 Hainan & K. pneumoniae & NDM & 32 & 2 & 4 & 0.5 & 0.38 & SHV-11, DHA-1, CTX-M-14 \\
\hline R093 Hebei & K. pneumoniae & NDM & 32 & 64 & 4 & 0.5 & 0.13 & SHV1, DHA-1, CTX-M-14 \\
\hline R094 Hebei & K. pneumoniae & NDM & 32 & 64 & 8 & 0.25 & 0.25 & SHV-12, DHA-1, CTX-M-14 \\
\hline R095 Hebei & K. pneumoniae & NDM & 32 & 2 & 8 & 0.25 & 0.38 & SHV-12, DHA-1, CTX-M-15 \\
\hline R096 Henan & K. pneumoniae & NDM & 16 & 64 & 16 & 0.5 & 1.01 & SHV1, DHA-1, CTX-M-15 \\
\hline R097 Henan & K. pneumoniae & NDM & 8 & 256 & 4 & 128 & 1.00 & SHV1, DHA-1, CTX-M-14 \\
\hline R098 Henan & K. pneumoniae & NDM & 256 & 64 & 32 & 1 & 0.14 & DHA-1 \\
\hline R100 Shanxi & K. pneumoniae & NDM & 8 & 32 & 4 & 32 & 1.50 & SHV-78, DHA-1, CTX-M-14 \\
\hline R101 Shanxi & K. pneumoniae & NDM & 256 & 128 & 16 & 1 & 0.07 & SHV-78, DHA-1, CTX-M-14 \\
\hline R102 Shanxi & K. pneumoniae & NDM & 32 & 256 & 4 & 1 & 0.13 & SHV-78, DHA-1, CTX-M-14 \\
\hline R103 Shanxi & K. pneumoniae & NDM & 128 & 64 & 32 & 0.25 & 0.25 & SHV1, DHA-1, CTX-M-15 \\
\hline R106 Sanxi & K. pneumoniae & NDM & 128 & 64 & 8 & 1 & 0.08 & SHV-12, DHA-1 \\
\hline R110 Sanxi & K. pneumoniae & NDM & 128 & 256 & 8 & 1 & 0.07 & SHV-12, DHA-1 \\
\hline R113 Sanxi & K. pneumoniae & NDM & 128 & 64 & 16 & 0.5 & 0.13 & SHV-12, DHA-1 \\
\hline R122 Tianjin & K. pneumoniae & NDM & 32 & 1 & 4 & 0.25 & 0.38 & SHV-12, DHA-1, CTX-M-14 \\
\hline R126 Tianjin & K. pneumoniae & NDM & 512 & 64 & 16 & 1 & 0.05 & SHV-12, DHA-1, CTX-M-14 \\
\hline R127 Tianjin & K. pneumoniae & NDM & 256 & 128 & 32 & 1 & 0.13 & SHV2, DHA-1 \\
\hline R128 Zhejiang & K. pneumoniae & NDM & 128 & 256 & 8 & 2 & 0.07 & SHV1, DHA-1 \\
\hline R129 Zhejiang & K. pneumoniae & NDM & 4 & 0.5 & 0.5 & 0.125 & 0.38 & SHV-12, DHA-1, CTX-M-15 \\
\hline R136 Zhejiang & K. pneumoniae & NDM & 256 & 64 & 16 & 1 & 0.08 & SHV-12, DHA-1 \\
\hline R148 Tianjing & K. pneumoniae & $\mathrm{KPC}-2, \mathrm{NDM}$ & 2048 & 8 & 256 & 2 & 0.38 & SHV-12, DHA-1, CTX-M-14 \\
\hline R153 Henan & K. pneumoniae & KPC-2,NDM & 2048 & 128 & 128 & 8 & 0.13 & SHV-12, DHA-1 \\
\hline
\end{tabular}



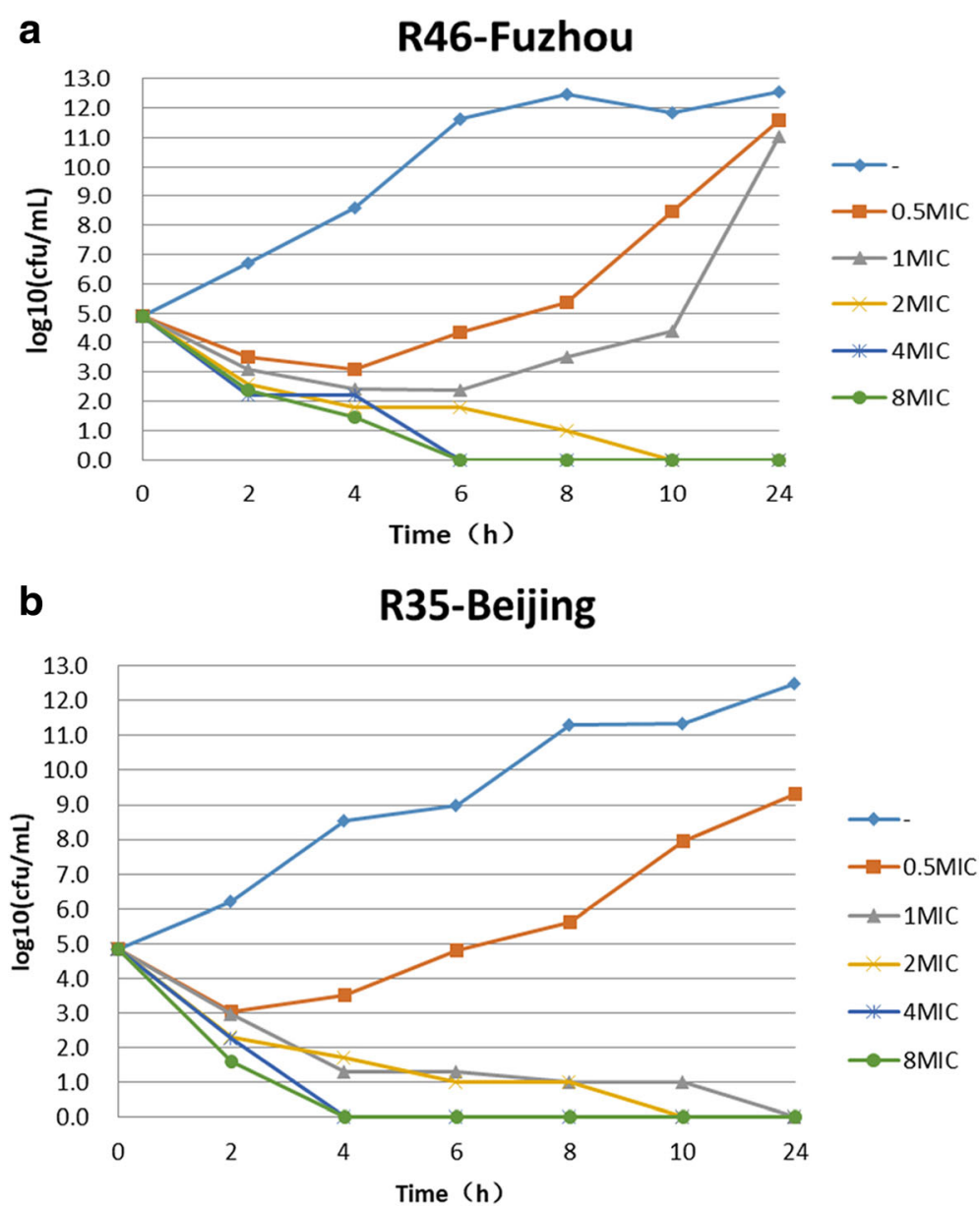

Fig. 1 Bactericidal curve plots of ceftazidime-avibactam at various concentrations against KPC-2 carbapenemase-producing Klebsiella pneumoniae

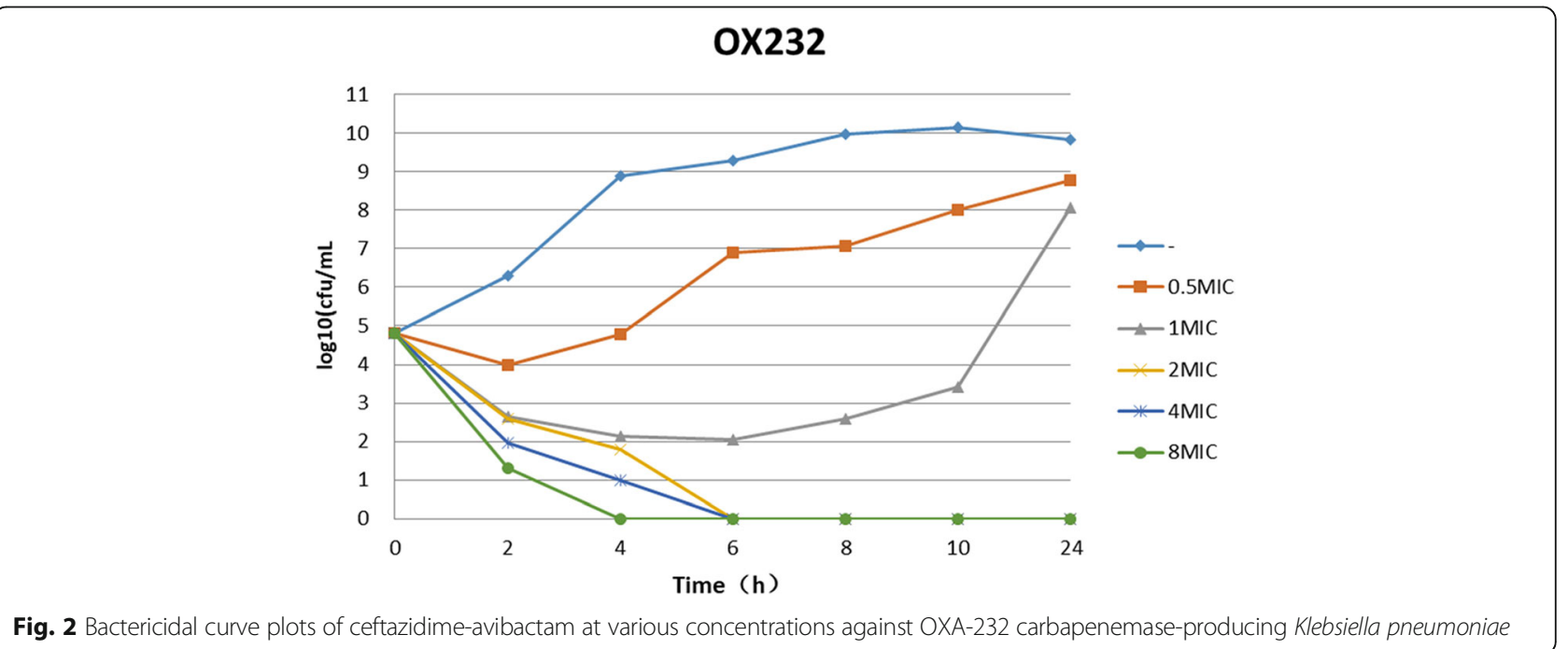

Fig. 2 Bactericidal curve plots of ceftazidime-avibactam at various concentrations against OXA-232 carbapenemase-producing Klebsiella pneumoniae 


\section{R126 Tianjin}

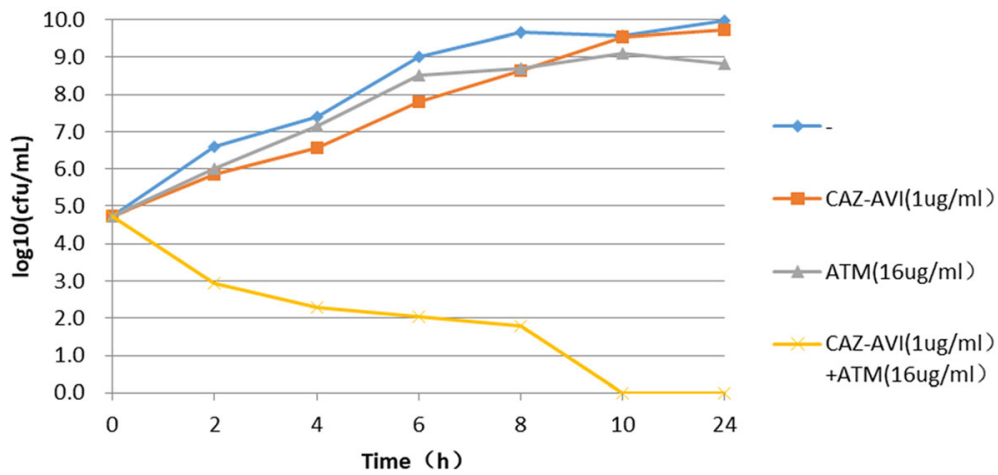

Fig. 3 Bactericidal curve plots of ceftazidime-avibactam combined with aztreonam against NDM carbapenemase-producing Klebsiella pneumoniae

showed a significant bactericidal effectiveness for either $b_{\text {KPC }}$ or bla $a_{\mathrm{OXA}-232}$ positive K. pneumoniae and the colony growth was undetected after $24 \mathrm{~h}$ incubation for most of strains (Fig. 1 and Fig. 2). For bla $a_{\text {NDM }}$ positive $K$. pneumoniae, ceftazidime-avibactam combined with aztreonam showed a significant bactericidal effectiveness and the colony growth was undetected after $10 \mathrm{~h}$ incubation (Fig. 3).

\section{Therapeutic efficacy of ceftazidime-avibactam against $K$. pneumoniae strain $\mathrm{Y} 8$ infection in mouse}

Mice were infected with $2.5 \times 10^{6} \mathrm{CFU}$ of strain $\mathrm{Y} 8$ and treated with PBS or ceftazidime-avibactam for 10 days. $70 \%$ of infection group mice died within 4 days, and all mice in this group died within 13 days (Fig. 4). All treatment group mice survived at $10 \mathrm{dpi}$ with the antibiotic applied every $8 \mathrm{~h}$, whereas $100 \%$ of mice in this group died within 4 days after the antibiotic treatment stopped (Fig. 4).

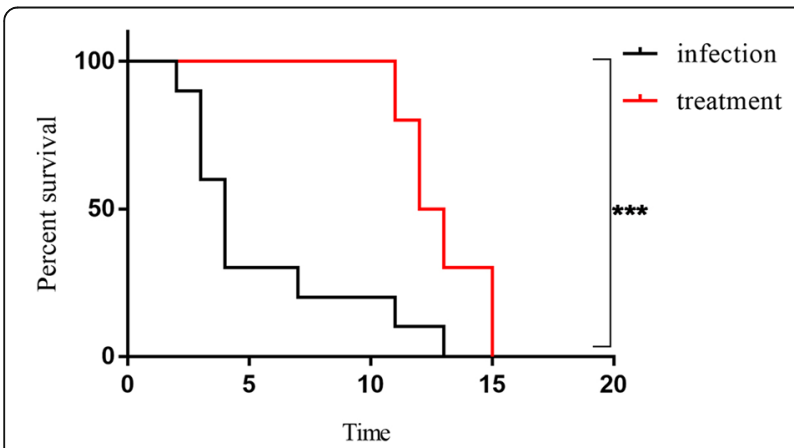

Fig. 4 Therapeutic efficacy of ceftazidime-avibactam against $K$. pneumoniae strain Y8 infection in mouse. Mice were infected with $2.5 \times 10^{6} \mathrm{CFU}$ of strain Y8 via the ip route and then treated with PBS or ceftazidime-avibactam by subcutaneous injection. Their survival was assessed daily for 15 days $(n=10)$. $* P<0.05$; $* * * P<0.001$
Bacterial load in the blood and tissues of mice

Mice were infected with $2.5 \times 10^{6} \mathrm{CFU}$ of strain Y8 via the ip and then treated with PBS or ceftazidime-avibactam. The viable bacteria were quantified in blood, liver and spleen at $3 \mathrm{dpi}$. The results showed that there was no significant difference in the amount of bacteria in the blood between the infected group and the treatment group. However, the spleen and liver of treatment group mice showed lower CFU counts, as compare with that of infected group, indicating that the antibiotic has significant effect on the bacteria and ceftazidime-avibactam led to a certain therapeutic efficacy (Fig. 5).

\section{Discussion}

In the recent decade, the prevalence and dissemination of CR-KP has posed a serious challenge in healthcare facilities in the world. The data from the Centers for Disease Control, USA disclosed the infection incidence of CR-KP increased from $1.2 \%$ in 2001 to $4.2 \%$ in 2011. In annual of 140,000 cases with Enterobacteriaceae infections, 9300 cases (6.6\%) were infected by these multidrug-resistant bacteria [17]. According to CHINET surveillance data, the resistance rate of Klebsiella pneumoniae to carbapenems were significantly increasing from 3\% in 2005 to $20 \%$ in 2017 [18]. Due to lack of effective antibacterial agents, infections due to CR-KP especially for hypervirulent Klebsiella pneumoniae usually accompany with high mortality $[19,20]$. Carbapenemases are the major resistance mechanism of Klebsiella pneumoniae to carbapenems. Currently, the common carbapenemase among $K$. pneumoniae clinical strains include Ambler class A, Ambler class B and Ambler class D (eg. bla $a_{\text {OXA-48, }}$, and $b l a_{\text {OXA-232). }}$. $b l a_{\mathrm{KPC}-2}$ is the most common carbapenemase in class A enzymes which can hydrolyze almost all of $\beta$-lactam antibiotics. bla $a_{\mathrm{NDM}}$ is the most common carbapenemase in class B metallo- $\beta$-lactamase which can hydrolyze all $\beta$-lactam antibiotics except aztreonam. Previous studies have shown the CR-KP strains isolated from children in China mainly 

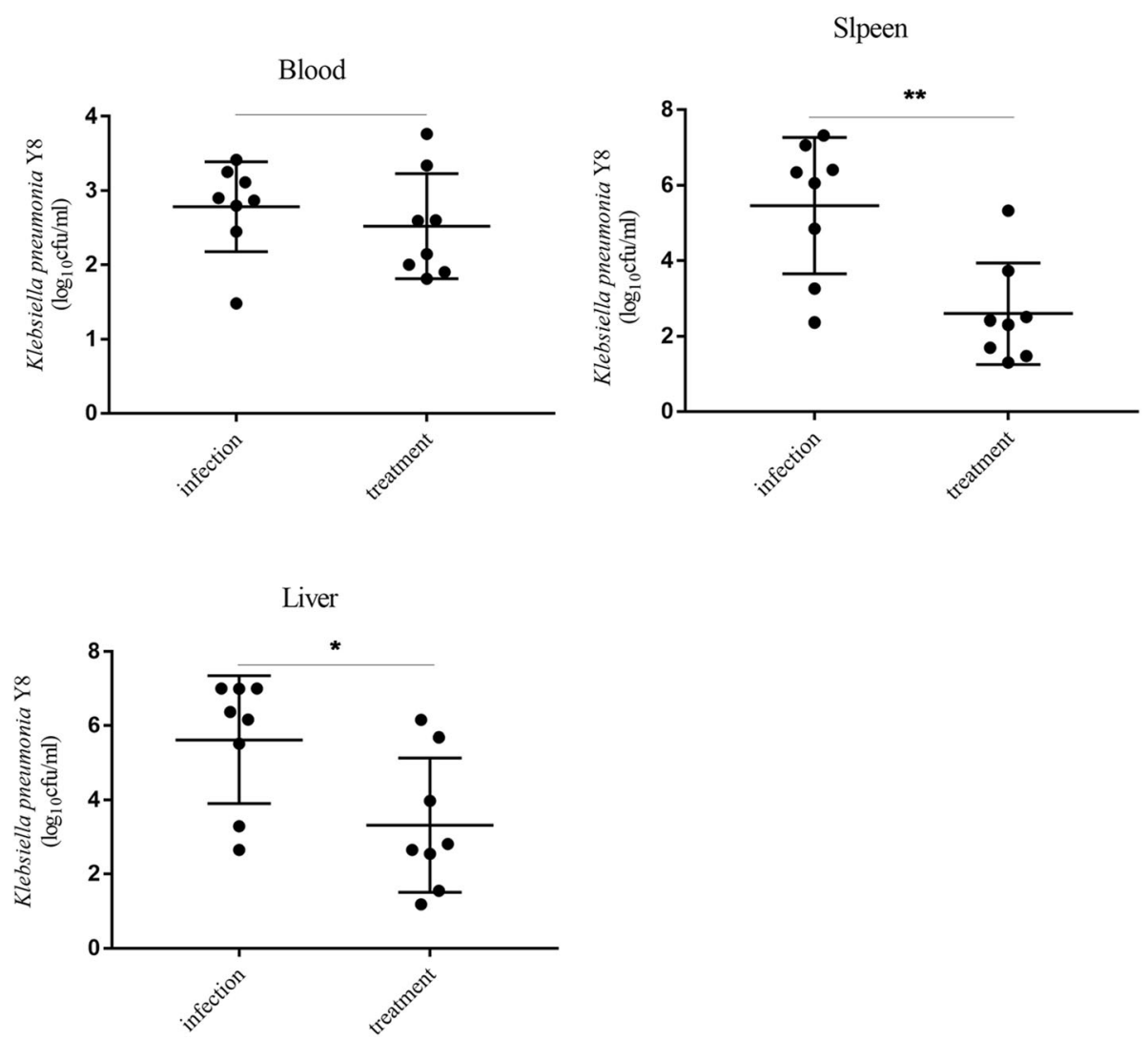

Fig. 5 Bacterial burden in blood, spleen and liver of mice at 3 days post infection (dpi). Mice were infected with $2.5 \times 10^{6} \mathrm{CFU}$ of strain Y8 via the ip route and then treated with PBS or ceftazidime-avibactam by subcutaneous injection. At $3 \mathrm{dpi}$, the viable bacteria of blood, spleen and liver was determined by plating serial dilutions on agar plates $(n=8) . * P<0.05 ; * * P<0.01$

produce $b l a_{\mathrm{NDM}}[21]$. bla $a_{\mathrm{OXA}-48}$ carbapenemase are predominantly existent in Klebsiella pneumoniae isolated in Tokyo and Europe [22]. In China, $b l a_{\mathrm{OXA}-181}$ and $b l a_{\mathrm{OXA}-232}$ have also been detected among Klebsiella pneumoniae clinical strains $[23,24]$.

Since CRE are usually extensively drug resistant, infections due to CRE are often associated with a high mortality. Therefore, a serious challenge of anti-infection therapy for CRE has been raised in clinical practice. Studies have revealed that compared to use carbapenems antibiotics alone, in the combination of carbapenems with other antibacterial agents such as tigecycline or polymyxin [25-28], amikacin [29] or fosfomycin [30] can considerably improve the outcomes of patient with CR-KP infection. Laurent adopted a combined pharmacotherapy regimen of dual carbapenems to provide a new approach in the treatment of CRE-induced infections [31]. As a novel $\beta$-lactam/ $\beta$-lactamase inhibitor, studies have shown that ceftazidime-avibactam can successfully cure the infections due to Enterobacteriaceae with bla $a_{\mathrm{KPC}}$ [32-35]. Nevertheless, it is worth to be noticed that with the increasing application of ceftazidime-avibactam, the resistant strains and failed cases have been reported $[6,7,36]$. Our results showed that all of $16 b l a_{\mathrm{KPC}-2}$ positive and 1 of $b l a_{\mathrm{OXA}-232}$ positive Klebsiella pneumoniae were susceptible to ceftazidime-avibactam with $\mathrm{MIC}_{50}$ and $\mathrm{MIC}_{90}$ for both $8 \mathrm{mg} / \mathrm{L}$. Time-kill assays demonstrated that it showed a significant bactericidal effectiveness for either $b l a_{\mathrm{KPC}}$ or bla $a_{\mathrm{OXA}-232}$ positive $K$. pneumoniae at the concentrations of $2 \mathrm{MIC}$, $4 \mathrm{MIC}$ or $8 \mathrm{MIC}$ of ceftazidime-avibactam. 1 and Fig. 2). At $1 \mathrm{MIC}$ of ceftazidime-avibactam, most of $K$. pneumoniae strains started to regrowth within 4-6h. These results mean that the dosage of ceftazidime-avibactam is very important in the treatment of infections caused by bla $a_{\mathrm{KPC}}$ or bla $a_{\mathrm{OXA}-232}$ positive K. pneumoniae [37].

In this study, $76.7 \%$ of $b l a_{\mathrm{NDM}}$ positive Klebsiella pneumoniae were resistance to ceftazidime-avibactam with $\mathrm{MIC}_{50}$ and $\mathrm{MIC}_{90}$ for $64 \mathrm{mg} / \mathrm{L}$ and $256 \mathrm{mg} / \mathrm{L}$, respectively. Because avibactam can not inhibit the activity of metallo- $\beta$-lactamase, ceftazidime-avibactam monotherapy was ineffective for infections caused by $b l a_{\mathrm{NDM}-1}$ positive Klebsiella pneumoniae [38]. According to the results of time-kill assay, ceftazidime-avibactam combined with aztreonam is necessary for the treatment of infection due to bla $a_{\mathrm{NDM}}$ positive $K$. pneumoniae based on the characteristics of weak hydrolysis capacity of metallo- $\beta$-lactamases to 
aztreonam. Eric Wenzler et al. also demonstrated that the combination of ceftazidime-avibactam and aztreonam had a synergistic bactericidal effect against class B metallo$\beta$-lactamase-producing gram-negative bacteria [39]. Simultaneously, Benjamin Davido et al. reported that two cases infected either with metallo- $\beta$-lactamase-producing Klebsiella pneumoniae or Pseudomonas aeruginosa were successfully cured by combined administration of ceftazidime-avibactam and aztreonam [40]. The results of antimicrobial susceptibility testing indicated 90\% (27/30) strains showed a synergistic effect for ceftazidime-avibactam combined with aztreonam. After combined with aztreonam, the MICs of ceftazidime-avibactam for 27 strains were reduced 4-256 times than ceftazidime-avibactam alone and all of them were susceptible to ceftazidime-avibactam with MIC $\leq 8 \mathrm{mg} / \mathrm{L}$. Subsequently, the bactericidal curve tests performed on 12 strains of Klebsiella pneumoniae with a synergistic effect were also shown the consistent synergistic bactericidal effects. The reduction of bacterial colonies number was $>2 \log _{10} \mathrm{CFU} / \mathrm{mL}$ compared with monotherapy and no colonies were detected after $24 \mathrm{~h}$. In addition to strain of R148 showing the synergism $8 \mathrm{~h}$ after combined therapy, three $b l a_{\mathrm{NDM}}$ positive Klebsiella pneumoniae clinical strains of R96, R97 and R100 did not demonstrate the synergistic effects after combined use with aztreonam, implying the other mechanisms of drug resistance may exist and require the further investigation in the future.

\section{Conclusions}

In summary, as a compound preparation of novel enzyme inhibitor, ceftazidime-avibactam possesses visible advantages in the treatment of class A and class D type carbapenemase-producing Klebsiella pneumoniae clinical isolates. In addition, if combined with aztreonam, it can also play a synergetic bactericidal effects against infections caused by bla NDM positive Klebsiella pneumoniae clinical strains.

\footnotetext{
Abbreviations

CAZ: Ceftazidime; CAZ-AVI: Ceftazidime-avibactam; CRE: Carbapenem-resistant Enterobacteriaceae; CR-KP: Carbapenem-resistant Klebsiella pneumoniae; FIC: Fractional inhibitory concentration; IPM: Imipenem; MEM: Meropenem; MIC: Minimal inhibitory concentration
}

\section{Acknowledgements}

We thank all the laboratories for contributing data to this analysis.

\section{Funding}

This work was supported by the National Natural Science Foundation of China (grant no. 81871690).

\section{Availability of data and materials}

The datasets used and/or analysed during the current study are available from the corresponding author on reasonable request.

\section{Authors' contributions}

$\mathrm{PH}$, and FPH designed the study. WXZ, YG, JYL and YYZ performed the experimental work. YY, DD, and DMZ collected the data. FPH analysed the data. All authors read and approved the final manuscript.
Ethics approval and consent to participate

This study was approved by Huashan hospital.

\section{Consent for publication \\ Not applicable.}

\section{Competing interests}

The authors declare that they have no competing interests.

\section{Publisher's Note}

Springer Nature remains neutral with regard to jurisdictional claims in published maps and institutional affiliations.

\section{Author details}

${ }^{1}$ Institute of Antibiotics, Huashan Hospital, Fudan University, 12 M. Wulumuqi Rd, Shanghai 200040, China. ${ }^{2}$ Department of Clinical Laboratory, Shuguang Hospital Affiliated to Shanghai University of Traditional Chinese Medicine, 528 Zhangheng Rd, Shanghai 201203, China. ${ }^{3}$ Department of Medical Microbiology and Immunology, Shanghai Jiao Tong University School of Medicine, Shanghai 200025, China. ${ }^{4}$ Key Laboratory of Clinical Pharmacology of Antibiotics, Ministry of Health, Shanghai, China.

Received: 23 September 2018 Accepted: 8 November 2018

Published online: 21 November 2018

\section{References}

1. Ducomble T, Faucheux S, Helbig U, Kaisers UX, Konig B, Knaust A, Lubbert C, Moller I, Rodloff AC, Schweickert B, Eckmanns T. Large hospital outbreak of KPC-2-producing Klebsiella pneumoniae: investigating mortality and the impact of screening for KPC-2 with polymerase chain reaction. J Hosp Infect. 2015;89:179-85.

2. Kim JO, Song SA, Yoon EJ, Shin JH, Lee H, Jeong SH, Lee K. Outbreak of KPC-2-producing Enterobacteriaceae caused by clonal dissemination of Klebsiella pneumoniae ST307 carrying an IncX3-type plasmid harboring a truncated Tn4401a. Diagn Microbiol Infect Dis. 2017:87:343-8.

3. Yang J, Ye L, Guo L, Zhao Q, Chen R, Luo Y, Chen Y, Tian S, Zhao J, Shen D, Han L. A nosocomial outbreak of KPC-2-producing Klebsiella pneumoniae in a Chinese hospital: dissemination of ST11 and emergence of ST37, ST392 and ST395. Clin Microbiol Infect. 2013;19:E509-15.

4. Liu J, Yu J, Chen F, Yu J, Simner P, Tamma P, Liu Y, Shen L. Emergence and establishment of KPC-2-producing ST11 Klebsiella pneumoniae in a general hospital in Shanghai, China. Eur J Clin Microbiol Infect Dis. 2018;37:293-9.

5. Zasowski EJ, Rybak JM, Rybak MJ. The beta-lactams strike Back: ceftazidime-avibactam. Pharmacotherapy. 2015;35:755-70.

6. Shields RK, Nguyen MH, Chen L, Press EG, Kreiswirth BN, Clancy CJ. Pneumonia and renal replacement therapy are risk factors for ceftazidime-avibactam treatment failures and resistance among patients with carbapenem-resistant Enterobacteriaceae infections. Antimicrob Agents Chemother. 2018;62:e02497-17.

7. Shields RK, Chen L, Cheng S, Chavda KD, Press EG, Snyder A, Pandey R, Doi Y, Kreiswirth BN, Nguyen MH, Clancy CJ. Emergence of ceftazidime-avibactam resistance due to plasmid-borne blaKPC-3 mutations during treatment of Carbapenem-resistant Klebsiella pneumoniae infections. Antimicrob Agents Chemother. 2017;61(3):e02097-16.

8. Zhu J, Sun L, Ding B, Yang Y, Xu X, Liu W, Zhu D, Yang F, Zhang H, Hu F. Outbreak of NDM-1-producing Klebsiella pneumoniae ST76 and ST37 isolates in neonates. Eur J Clin Microbiol Infect Dis. 2016;35(4):611-8.

9. Woodford N, Fagan EJ, Ellington MJ. Multiplex PCR for rapid detection of genes encoding CTX-M extended-spectrum (beta)-lactamases. J Antimicrob Chemother. 2006;57(1):154-5.

10. Poirel L, Walsh TR, Cuvillier V, Nordmann P. Multiplex PCR for detection of acquired carbapenemase genes. Diagn Microbiol Infect Dis. 2011;70(1):119-23.

11. Clinical and Laboratory Standards Institute. Performance Standards for Antimicrobial Susceptibility Testing[S]: Twenty-seventh Informational Supplement. PA: CLSI; 2017.

12. Bercot $B$, Poirel L, Dortet $L$, Nordmann P. In vitro evaluation of antibiotic synergy for NDM-1-producing Enterobacteriaceae. J Antimicrob Chemother. 2011;66:2295-7.

13. Elemam A, Rahimian J, Doymaz M. In vitro evaluation of antibiotic synergy for polymyxin B-resistant carbapenemase-producing Klebsiella pneumoniae. J Clin Microbiol. 2010;48:3558-62. 
14. Gunderson BW, Ibrahim KH, Hovde LB, Fromm TL, Reed MD, Rotschafer JC Synergistic activity of colistin and ceftazidime against multiantibioticresistant Pseudomonas aeruginosa in an in vitro pharmacodynamic model. Antimicrob Agents Chemother. 2003;47:905-9.

15. Paevskii SA. A means for determining the bactericidal activity of the tissues during the treatment of orthopedic patients by transosseous osteosynthesis methods. Klin Lab Diagn. 1993:25-9.

16. Norden CW, Wentzel H, Keleti E. Comparison of techniques for measurement of in vitro antibiotic synergism. J Infect Dis. 1979;140:629-33.

17. US Centers for Disease Control and Prevention. Antibiotic Resistance Theats in the United States. 2013. https://www.cdc.gov/drugresistance/threatreport-2013/pdf/ar-threats-2013-508.pdf.

18. Hu FP, Guo Y, Zhu DM, Wang F, Jiang XF, Xu YC, Zhang XJ, Zhang CX, Ji P, Xie Y, Kang M, Wang CQ, Wang AM, Xu YH, Shen JL, Sun ZY, Chen ZJ, Ni YX, Sun JY, Chu YZ, Tian SF, Hu ZD, Li J, Yu YS, Lin J, Shan B, Du Y, Han Y, Guo S, Wei LH, Wu L, Zhang H, Kong J, Hu YJ, Ai XM, Zhuo C, Su DH, Yang Q, Jia B, Huang W. Resistance trends among clinical isolates in China reported from CHINET surveillance of bacterial resistance, 2005-2014. Clin Microbiol Infect. 2016;22(Suppl 1):S9-14.

19. Chew KL, Lin RTP, Teo JWP. Klebsiella pneumoniae in Singapore: Hypervirulent infections and the Carbapenemase threat. Front Cell Infect Microbiol. 2017;7:515.

20. Kohler PP, Volling C, Green K, Uleryk EM, Shah PS, McGeer A. Carbapenem resistance, initial antibiotic therapy, and mortality in Klebsiella pneumoniae bacteremia: a systematic review and meta-analysis. Infect Control Hosp Epidemiol. 2017;38:1319-28.

21. Javed H, Ejaz H, Zafar A, Rathore AW, Ikram ul H. Metallo-beta-lactamase producing Escherichia coli and Klebsiella pneumoniae: a rising threat for hospitalized children. J Pak Med Assoc. 2016;66:1068-72.

22. Ma L, Wang JT, Wu TL, Siu LK, Chuang YC, Lin JC, Lu MC, Lu PL. Emergence of OXA-48-producing Klebsiella pneumoniae in Taiwan. PLoS One. 2015;10: e0139152

23. Liu $Y$, Feng $Y$, Wu W, Xie $Y$, Wang $X$, Zhang $X$, Chen $X$, Zong Z. First report of OXA-181-producing Escherichia coli in China and characterization of the isolate using whole-genome sequencing. Antimicrob Agents Chemother. 2015;59(8):5022-5.

24. Yin D, Dong D, Li K, Zhang L, Liang J, Yang Y, Wu N, Bao Y, Wang C. Hu F. clonal dissemination of OXA-232 Carbapenemase-producing Klebsiella pneumoniae in neonates. Antimicrob Agents Chemother. 2017:61(8): e00385-17.

25. Tzouvelekis LS, Markogiannakis A, Piperaki E, Souli M, Daikos GL. Treating infections caused by carbapenemase-producing Enterobacteriaceae. Clin Microbiol Infect. 2014:20:862-72.

26. Qureshi ZA, Paterson DL, Potoski BA, Kilayko MC, Sandovsky G, Sordillo E, Polsky B, Adams-Haduch JM, Doi Y. Treatment outcome of bacteremia due to KPC-producing Klebsiella pneumoniae: superiority of combination antimicrobial regimens. Antimicrob Agents Chemother. 2012;56:2108-13.

27. Zhang Y, Li P, Yin Y, Li F, Zhang Q. In vitro activity of tigecycline in combination with rifampin, doripenem or ceftazidime against carbapenemresistant Klebsiella pneumoniae bloodstream isolates. J Antibiot (Tokyo). 2017;70:193-5.

28. Machuca I, Gutierrez-Gutierrez B, Gracia-Ahufinger I, Rivera Espinar F, Cano A, Guzman-Puche J, Perez-Nadales E, Natera C, Rodriguez M, Leon R, Caston JJ, Rodriguez-Lopez F, Rodriguez-Bano J, Torre-Cisneros J. Mortality associated with bacteremia due to Colistin-resistant Klebsiella pneumoniae with high-level Meropenem resistance: importance of combination therapy without Colistin and Carbapenems. Antimicrob Agents Chemother. 2017;61:e00406-17.

29. Hajjej Z, Gharsallah H, Naija H, Boutiba I, Labbene I, Ferjani M. Successful treatment of a Carbapenem-resistant Klebsiella pneumoniae carrying Bla OXA-48, Bla VIM-2, Bla CMY-2 and Bla SHV- with high dose combination of imipenem and amikacin. IDCases. 2016:4:10-2.

30. Albiero J, Sy SK, Mazucheli J, Caparroz-Assef SM, Costa BB, Alves JL, Gales AC, Tognim MC. Pharmacodynamic evaluation of the potential clinical utility of Fosfomycin and Meropenem in combination therapy against KPC-2-producing Klebsiella pneumoniae. Antimicrob Agents Chemother. 2016;60:4128-39.

31. Poirel $L$, Kieffer $N$, Nordmann P. In vitro evaluation of dual carbapenem combinations against carbapenemase-producing Enterobacteriaceae. J Antimicrob Chemother. 2016;71:156-61.

32. Gugliandolo A, Caio C, Mezzatesta ML, Rifici C, Bramanti P, Stefani S, Mazzon E. Successful ceftazidime-avibactam treatment of MDR-KPC-positive Klebsiella pneumoniae infection in a patient with traumatic brain injury: a case report. Medicine (Baltimore). 2017;96:e7664.
33. Temkin E, Torre-Cisneros J, Beovic B, Benito N, Giannella M, Gilarranz R, Jeremiah C, Loeches B, Machuca I, Jimenez-Martin MJ, Martinez JA, MoraRillo M, Navas E, Osthoff M, Pozo JC, Ramos Ramos JC, Rodriguez M, Sanchez-Garcia M, Viale P, Wolff M, Carmeli Y. Ceftazidime-avibactam as salvage therapy for infections caused by Carbapenem-resistant organisms. Antimicrob Agents Chemother. 2017;61:e01964-16.

34. Holyk A, Belden V, Lee JJ, Musick W, Keul R, Britz GW, Lin J. Ceftazidime/ avibactam use for carbapenem-resistant Klebsiella pneumoniae meningitis: a case report. J Antimicrob Chemother. 2018;73:254-6.

35. van Duin D, Lok JJ, Earley M, Cober E, Richter SS, Perez F, Salata RA, Kalayjian RC, Watkins RR, Doi Y, Kaye KS, Fowler VG, Jr., Paterson DL Bonomo RA, Evans S, Antibacterial Resistance Leadership G. Colistin versus ceftazidime-avibactam in the treatment of infections due to Carbapenemresistant Enterobacteriaceae. Clin Infect Dis. 2018;66:163-71.

36. Barnes MD, Winkler ML, Taracila MA, Page MG, Desarbre E, Kreiswirth BN, Shields RK, Nguyen MH, Clancy C, Spellberg B, Papp-Wallace KM, Bonomo RA. Klebsiella pneumoniae Carbapenemase-2 (KPC-2), substitutions at ambler position Asp179, and resistance to ceftazidime-avibactam: unique antibioticresistant phenotypes emerge from beta-lactamase protein engineering. MBio. 2017:8:e00528-17.

37. Bensman TJ, Wang J, Jayne J, Fukushima L, Rao AP, D'Argenio DZ, Beringer PM. Pharmacokinetic-Pharmacodynamic target attainment analyses to determine optimal dosing of ceftazidime-avibactam for the treatment of acute pulmonary exacerbations in patients with cystic fibrosis. Antimicrob Agents Chemother. 2017;61:e00988-17.

38. Davido B, Senard O, de Truchis P, Salomon J, Dinh A. Monotherapy of ceftazidime-avibactam and ceftolozane-tazobactam: two effective antimicrobial agents against multidrug-resistant organisms except for NDM1 isolates. Int J Infect Dis. 2017;62:124-5.

39. Wenzler E, Deraedt MF, Harrington AT, Danizger LH. Synergistic activity of ceftazidime-avibactam and aztreonam against serine and metallo-betalactamase-producing gram-negative pathogens. Diagn Microbiol Infect Dis. 2017:88:352-4.

40. Davido B, Fellous L, Lawrence C, Maxime V, Rottman M, Dinh A. Ceftazidime-avibactam and Aztreonam, an interesting strategy to overcome beta-lactam resistance conferred by Metallo-beta-lactamases in Enterobacteriaceae and Pseudomonas aeruginosa. Antimicrob Agents Chemother. 2017;61:e01008-17.

\section{Ready to submit your research? Choose BMC and benefit from:}

- fast, convenient online submission

- thorough peer review by experienced researchers in your field

- rapid publication on acceptance

- support for research data, including large and complex data types

- gold Open Access which fosters wider collaboration and increased citations

- maximum visibility for your research: over $100 \mathrm{M}$ website views per year

At BMC, research is always in progress.

Learn more biomedcentral.com/submissions 